Research article

\title{
A new automated method for the determination of the Total Antioxidant Capacity (TAC) of human plasma, based on the crocin bleaching assay

\author{
Marilena Kampa1 ${ }^{1}$, Anastasia Nistikaki1 , Vassilios Tsaousis ${ }^{3}$, Niki Maliaraki², \\ George Notas ${ }^{4}$ and Elias Castanas*1
}

Address: ${ }^{1}$ Laboratories of Experimental Endocrinology, University of Crete, School of Medicine, Heraklion, GR-71110, Greece, ${ }^{2}$ Clinical Chemistry University of Crete, School of Medicine, Heraklion, GR-71110, Greece, ${ }^{3}$ Medicon Hellas S.A., Gerakas, GR-15344, Greece and ${ }^{4}$ Gastroenterology, University of Crete, School of Medicine, Heraklion, GR-71110, Greece

E-mail: Marilena Kampa - kampa@med.uoc.gr; Anastasia Nistikaki - labendo@med.uoc.gr; Vassilios Tsaousis - R\&D@mediconsa.com; Niki Maliaraki - nikim@acs.gr; George Notas - chief@med.uoc.gr; Elias Castanas* - castanas@med.uoc.gr

${ }^{*}$ Corresponding author

Published: 28 August 2002

Received: 9 May 2002

BMC Clinical Pathology 2002, 2:3

Accepted: 28 August 2002

This article is available from: http://www.biomedcentral.com/l472-6890/2/3

(C) $2002 \mathrm{Kampa}$ et al; licensee BioMed Central Ltd. This article is published in Open Access: verbatim copying and redistribution of this article are permitted in all media for any non-commercial purpose, provided this notice is preserved along with the article's original URL.

\begin{abstract}
Background: Antioxidant molecules, which scavenge free radical species to prevent or delay oxidative damage of important macromolecules, membrane lipids and lipoproteins, are prevalent in plasma and other biological fluids. Among them, bilirubin, uric acid and protein thiols are the major endogenous antioxidants, while vitamins $\mathrm{C}$ and $\mathrm{E}$, as well as a number of food-derived (poly)aromatic substances, belonging to stilbens, flavonoids and phenolic acids, are the main classes of nutritional antioxidants. Assays for total antioxidant capacity in plasma differ in their type of oxidation source, target and measurement used to detect the oxidized product.

Methods: In the present work we present an automated assay for the estimation of blood total antioxidant capacity (TAC assay), based on the crocin bleaching (oxidation) method. This method was adapted on a modern autoanalyzer, was linear over a wide range of values $(0-3 \mathrm{mmol} / \mathrm{L})$, and performed using an end point measurement.

Results: The TAC method presented a linear correlation with another automated commercial Total Antioxidant Status (TAS) test. Detection of the interference of different metabolites revealed a significant participation of TAC from uric acid, bilirubin, albumin, a minor interference from ascorbic acid, and no interference from hemoglobin. TAC was not modified by two freeze/thawing cycles, and was stable in samples stored at room temperature for 4 hours. K-EDTA and heparin were the best anticoagulants, while citrate decreased TAC by $20 \%$. Reference values derived from samples of normal blood donors was $1.175 \pm 0.007 \mathrm{mmol} / \mathrm{L}$ (mean \pm SEM), while a diet rich in antioxidants more than doubled this value.

Conclusions: The proposed TAC assay, is fully automated, stable and reliable, and could be of value in the estimation of the AC of plasma. It is further proposed to calculate the antioxidant capacity of plasma after a subtraction of all interference deriving from endogenous and/or exogenous metabolites. The antioxidant capacity of plasma thus calculated can be used as a useful indicator of the antioxidant value of foods and beverages in the daily diet.
\end{abstract}




\section{Background}

Evidence from biochemical and animal models suggests that nutritional antioxidants protect against the development of chronic diseases, including coronary heart disease, atherosclerosis and certain forms of cancers. However, this hypothesis is not clearly corroborated by intervention studies in human subjects, due, in part, to inadequacies in current analytical methodologies. Indeed, although in vitro assays may give useful information on the attributes required by a compound to act as an antioxidant, results have limited nutritional relevance [1], since plasma and other biological fluids abound in antioxidant molecules, which scavenge free radical species thus reducing oxidative damage of either macromolecules, membrane lipids or lipoproteins. Bilirubin, uric acid and protein thiols are major endogenous antioxidants, while vitamins $\mathrm{C}$ and $\mathrm{E}$, as well as a number of food-derived (poly)aromatic substances, belonging to stilbenes, flavonoids and phenolic acids are the main classes of nutritional antioxidants [2-5].

Assays for total antioxidant capacity in plasma differ in their type of oxidation source, target and measurement used to detect the oxidized product. These assays give a wide range of results, should never be used in isolation, and results should be interpreted with caution [1]. To counteract these limitations, several methods have been proposed for determination of total plasma antioxidant capacity (TAC). They can be divided in two main classes: Either distinct antioxidant components are assayed (ex. Vitamin E, ascorbic acid, etc), or the total antioxidant potency is estimated by the combined reducing activities of a given body fluid (especially plasma). A number of methods have been developed for this later estimation, given the considerable interest in antioxidants as bioactive components of food and as nutritional agents with a role in the maintenance of health and in disease prevention [6]. Indeed, there are situations in which knowledge of the individual levels of specific antioxidant components might be less useful than the total antioxidant potency of the medium concerned. Such situations might be in the understanding of structure-activity relationships of pure antioxidant compounds, in the determination of the antioxidant contributions of specific dietary components and how this relates to the antioxidant composition and activities of the individual constituents, and in the study of decreases in plasma antioxidant activity in individuals under oxidative stress in specific disease states [7]. The total antioxidant activity of plasma has been assayed by a number of different methods including oxygen consumption during lipid peroxidation [8], luminol-enhanced chemiluminescence [9], measurement of R-phycoerythrin bleaching [ORAC method [10-12]], sensitivity of erythrocytes to hemolysis [13], ferric reducing activity [14], lipid peroxides generation $[15,16]$, and finally carotenoid (crocin) bleaching [17]. This latter method has been used in food chemistry for assaying the antioxidant capability of complex food mixtures. A recent development of this method, based on serial dilutions of human plasma, has been recently reported, allowing the determination of the plasma antioxidant activity in humans [18]. The present work builds on these data, proposes additional modifications and attempts to automate it, in order to meet the requirements and capacities of modern autoanalyzers.

\section{Methods \\ Materials}

Chemicals and Biochemicals

2,2'-Azobis-(2-amidinopropane) dihydrochloride (ABAP) and 6-hydroxy-2,5,7,8-tetramethylchroman-2carboxylic acid (Trolox C) were purchased from SigmaAldrich (Milwaukee, WI). ABAP was dissolved just before use with a $10 \mathrm{mM}$ Phosphate buffer ( $\mathrm{pH}$ 7.4) at concentrations varying from $4-10 \mathrm{mg} / \mathrm{ml}$. The usual concentration used was $5 \mathrm{mg} / \mathrm{ml}$. Saffron (Greek red saffron of the COUPE class) was purchased from the Association of Saffron producers (Krokos, Kozani, GR). All other chemicals and biochemicals were from Sigma (St Louis, MO), or Merck (Darmstad, De). Crocin was isolated from saffron by water/methanol extraction after repeated extraction with ethyl-ether, as described previously [18]. After extraction, crocin was tested for purity (absorbance peak at 440 and a shoulder at 464), diluted in 30\% methanol in water, diluted fivefold with phosphate buffer (10 mM, $\mathrm{pH} 7.4)$, and the concentration of crocin was adjusted to $20 \mu \mathrm{M}$ with buffer, using the molecular absorbance coefficient of crocin $\epsilon_{443}=89000 \mathrm{M}^{-1} \mathrm{~cm}^{-1}$ [19]. Aliquots of crocin, protected from light, weres to redat $-20^{\circ} \mathrm{C}$, until use. Caffeic (97\%), ferulic (99\%) and protocatechuic (99\%) acids were purchased from Sigma-Aldrich Chemical Co. (Milwaukee, WI). Sinapic (98\%), syringic (98\%), 3,4-dihydroxyphenylacetic acids and epigalocatechin were from Sigma Chemical Co. (St. Loui, MO), while quercetine was a kind gift from Prof. J. Vercauteren (University of Bordeaux I, France).

\section{Instruments}

Spectrophotometric determinations were performed with a Kontron Uvicon 860 Spectrophotometer (Paris, France). An Athos 2001 microplate reader (Vienna, Austria), with a filter at $450 \mathrm{~nm}$ was used for initial microplate assay. Later, the automated microplate apparatus Triturus (Grifols, Barcelona, Spain), equipped with a pipettor, an incubator and a reader station, connected and driven from a PC station was used. Finally, the Olympus AU 400 autoanalyzer was used for the automated assay. 

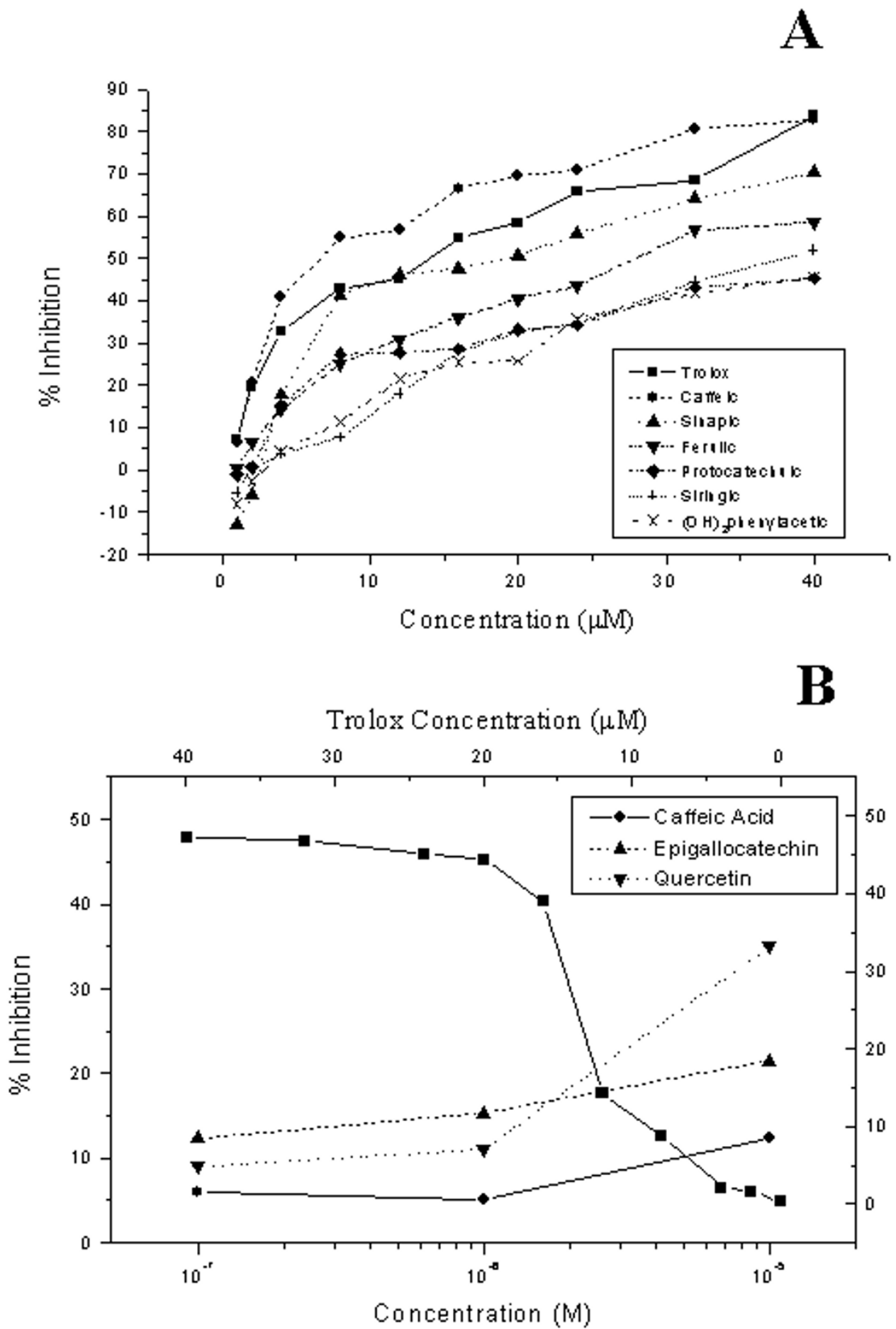

Figure I

Antioxidant capacity of a number of phenolic acids (A) and polyphenols (B) on the TAC assay. The indicated concentrations of different phenolic acids $(A)$ and purified polyphenols $(B)$ were assayed for their inhibitory effect of crocin oxidation, over the range $0-10 \mu \mathrm{g} / \mathrm{ml}$ for phenolic acids and $10^{-7}-10^{-5} \mathrm{M}$ for polyphenols. A Trolox standard curve is presented for comparison. 


\section{Methods \\ Colorimetric method for the determination of the TAC of human plasma}

The method for manual TAC plasma determination was previously described by Lusignoli et al [18]. In brief, in each well of the microplate $100 \mu \mathrm{l}$ of crocin and $50 \mu \mathrm{l}$ of the plasma sample, diluted in phosphate buffer were pipetted. The reaction was initiated with the addition of 100 $\mu \mathrm{l}$ of prewarmed $\left(37^{\circ} \mathrm{C}\right) \operatorname{ABAP}(5 \mathrm{mg} / \mathrm{ml})$, and crocin bleaching was made by incubating the plate at a humidified thermostated oven at $37^{\circ} \mathrm{C}$, for $60-75$ min. Blanks consisted of crocin, plasma samples, and phosphate buffer (100, 50 and $100 \mu$ respectively) were run in parallel. The absorbance was measured at $450 \mathrm{~nm}$. The specific absorbance was then calculated by subtracting the corresponding blank value, and the antioxidant activity was calculated as the ratio: $100 \times\left(\mathrm{Abs}_{0}-\mathrm{Abs}_{\text {sample }}\right) / \mathrm{Abs}_{0}$, in which $\mathrm{Abs}_{0}$ was the absorbance in the absence of antioxidants, and $\mathrm{Abs}_{\text {sample }}$ was the absorbance in the presence of sample. A standard curve of the water-soluble synthetic antioxidant Trolox, prepared prior to use, ranging from $0-$ $10 \mu \mathrm{g} . \mathrm{ml}$ was equally assayed under the same conditions.

\section{Automation of TAC method}

The above method was adapted to the Triturus microplate automate, using exactly the above-described protocol. The adaptation of the method to the Olympus autoanalyzer was based on the measurement of the inhibition that is caused by total antioxidants on the bleaching of crocin from ABAP. The procedure was as follows: A concentration of crocin isolated from saffron as previously described [18], was adjusted at $25 \mu \mathrm{M}$ with $10 \mathrm{mM}$ phosphate buffer, pH 7.4 (A) and mixed with an inert filler at a final concentration of $7.5 \%(\mathrm{w} / \mathrm{w})$. Three $\mathrm{ml}$ of the above solution were dispensed into glass vials, lyophilized on BOC Edwards Calumatic Lyoflex 0.8 lyophilizer and sealed under vacuum after the end of lyophilization. Each vial was reconstituted with $7.5 \mathrm{ml}$ of buffer A prior to use. The reconstituted solution was $\mathrm{R} 1$ of the final assay while R2 was a ready-to-use liquid reagent containing 50 $\mathrm{mg} / \mathrm{ml}$ ABAP in buffer A. For the automated procedure a blank reagent was run together with the above-described reagent. The blank reagent was consisted of buffer $A$ as $\mathrm{R} 1_{\text {blank }}$ and $50 \mathrm{mg} / \mathrm{ml} \mathrm{ABAP}$ in buffer $\mathrm{A}$ as $\mathrm{R} 2_{\text {blank }}$.

The assay was performed at $37^{\circ} \mathrm{C}$ in the following steps: Two $\mu$ l of sample, calibrator or control were mixed with $250 \mu \mathrm{l}$ of crocin reagent (R1) and this mixture was incubated for $160 \mathrm{~s}$. Thereafter, $250 \mu \mathrm{l}$ ABAP reagent R2 were added and the decrease in absorbance at $450 \mathrm{~nm}$ was measured 256 s later. An analogous reaction was performed for the sample blank assay using blank reagents, as mentioned above. The difference between the two signals for the reaction and the reagent blank reaction (the reaction using deionised water as sample) was used to es- tablish the standard curve and to calculate values of controls and serum samples. The result was always negative, indicating an inhibition in the development of color compared to the reaction in the absence of antioxidants i.e., sample.

All biochemical parameters were assayed on an Olympus AU400 autoanalyzer. Reagent for the measurement of Uric acid was from OLYMPUS Diagnostica GmbH, Lismmehan, Ireland and the reagent for TAS activity was from RANDOX Laboratories Ltd, United Kingdom. All other reagents were from Sigma (St Louis, MO) except where indicated.

For the interference studies we used the following materials: Hemoglobin: Erythrocytes were washed with physiological saline, and a hemoglobin solution was prepared through hemolysis, by adding distilled water. Bilirubin: Crystallized bilirubin was dissolved into a very small quantity of weak alkaline $(0.1 \mathrm{~N} \mathrm{NaOH})$ solution. Conjugated Bilirubin: Conjugated bilirubin (CalbioChem, La Jolla, CA) was dissolved into a very small quantity of water. Turbidity: Intralipid 10\% (Pharmacia (Hellas) SA, Athens, Greece) was used with no further treatment. Ascorbate: (Merck, Darmstadt, Germany) was dissolved into distilled water. Bovine serum albumin (protease free): Serological Products (IL).

All biochemical parameters were assayed on an Olympus AU 400 autoanalyzer, with Olympus reagents provided from Medicon Hellas (Gerakas, Greece). (Albumin OSR6102, total bilirubin OSR6112, iron OSR6123 uric acid OSR6136).

\section{Blood samples}

Forty healthy blood donors, aged 21-52 years (28 males, and 12 females) from the region of Heraklion, Crete, were used for the determination of the reference interval of the TAC assay. They were on a normal diet, while we had little information of their nutritional and smoking habits. In addition, one hundred samples from the hematology laboratory of the Heraklion University Hospital, with no indication of the underlying pathology were further used for the correlation of TAC assay with the uric acid, bilirubin, iron and protein concentrations. Finally, 17 nuns, from an orthodox monastery in the region of Heraklion were assayed, after a 40 days ritual fasting before Easter. This fasting consisted in the abolishment of all animal food from their diet.

Blood samples were usually collected on $\mathrm{K}_{3}$-EDTA, and immediately centrifuged in a refrigerated centrifuge. They were aliquoted, and stored at $-80^{\circ} \mathrm{C}$ until use. 

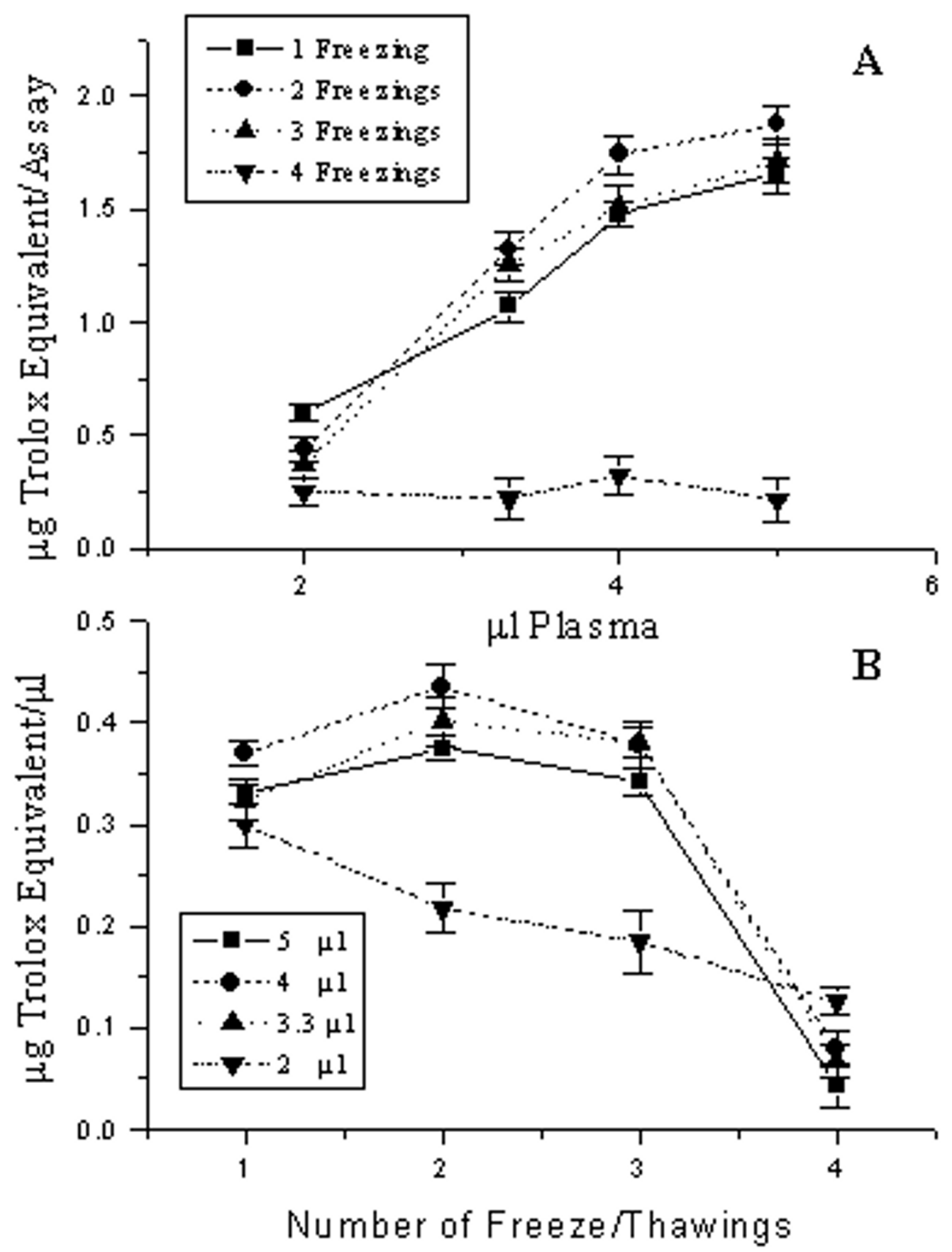

\section{Figure 2}

Effect of freeze/thawing cycles on the plasma concentration of TAC. Ten different plasmas, collected on K-EDTA were assayed for TAC following the manual method described in the Material and Methods section. In A, different plasma volumes were assayed after I-4 freezing cycles. In B, the calculated TAC concentration per $\mu$ l of plasma was reported over the number of freezing cycles. Mean \pm SEM of 10 different plasma samples, from normal individuals. 
Table I: Effect of different anticoagulants and blood preservation on the TAC assay. Results are presented as mean \pm SEM of ten different assays, and expressed as $\mathrm{mmol} / \mathrm{L}$.

\begin{tabular}{llll}
\hline StorageConditions & $\begin{array}{l}\text { Immediate plasma separa- } \\
\text { tion }\end{array}$ & $\begin{array}{l}\text { Storage at room tempera- } \\
\text { ture for } 4 \text { hours }\end{array}$ & Storage at $4^{\circ} \mathrm{C}$ for 4 hours
\end{tabular}

\section{Anticoagulant}

\begin{tabular}{|c|c|c|c|}
\hline None (serum) & $1.09 \pm 0.04$ & $1.10 \pm 0.03$ & $1.09 \pm 0.03$ \\
\hline K-EDTA & $1.03 \pm 0.05$ & $1.02 \pm 0.03$ & $1.01 \pm 0.04$ \\
\hline Citrate & $0.82 \pm 0.04$ & $0.81 \pm 0.03$ & $0.83 \pm 0.03$ \\
\hline Heparin & $1.04 \pm 0.05$ & $1.08 \pm 0.04$ & $1.04 \pm 0.04$ \\
\hline
\end{tabular}

\section{Statistical analysis}

The statistical analysis of the results was performed using parametric methods, with the aid of the Origin v 5.0 (Microcal Software, Northampton, MA) and the Systat $\mathrm{v} 10.0$ (SPSS, Chicago, IL) microcomputer programs.

\section{Results \\ Validation of the assay \\ Reagents and antioxidants}

As indicated in the original paper for the assay [18], crocin spectra in the oxidized and the reduced form present an absorption maximum at $440 \mathrm{~nm}$. This was also verified in the present work (not shown). In addition, different concentrations of ABAP, in the presence of $5 \mu \mathrm{M}$ crocin, were assayed. Concentrations of $4-5 \mathrm{mg} / \mathrm{ml}$ produced a very sensitive curve, while the sensitivity was lost at ABAP concentrations $>6 \mathrm{mg} / \mathrm{ml}$. In view of these results, an ABAP concentration of $5 \mathrm{mg} / \mathrm{ml}$ was chosen. On the other hand, an optimum crocin concentration of $5 \mu \mathrm{M}$ was chosen, after a series of different dilutions, ranging from 2 to $20 \mu \mathrm{M}$, concentrations which, after 60-75 min incubations generated similar curves as in the original publication [18].

A series of antioxidant phenolic acids, found in a number of foods was tested for inhibition of crocin, in the assay generated by the use of the above concentrations of ABAP and crocin. The results are presented in Figure 1A. As shown, all phenolic acids produced a dose-dependent inhibition of crocin oxidation. Caffeic acid was the most potent inhibitor of crocin oxidation, followed by sinapic and ferulic acid. Protocatechuic, siringic and dihydrophenyl acetic acids exhibited the lower antioxidant activity, a result reported previously in other in vitro systems [20]. Figure $1 \mathrm{~B}$ on the other hand, presents the crocin inhibition in the presence of two polyphenols: quercetine and epigallocatechin. As shown, both polyphenols produce a dose-dependent inhibition of crocin oxidation, indicating that the assay could be used for the determination of anti- oxidants in a number of natural products, such as wine, olive oil or tea.

\section{Plasma}

In the original assay, serial dilutions of plasma were tested for their inhibitory activity on crocin oxidation by ABAP, the antioxidant capacity of the plasma was calculated by the sigmoidal fitting of the resulting curve, and the calculation of the $\mathrm{IC}_{50}$, reported finally to the Trolox inhibitory curve. In the present work, the inhibitory activity of human plasma on crocin oxidation was directly reported to the Trolox curve, and the equivalent Trolox activity was directly calculated. Long incubation times $(60-75 \mathrm{~min})$ were used, in order to minimize the lag time of antioxidant activity reported in the initial kinetic assay of crocin bleaching [17]. For this purpose, we have linearized the Trolox curve through a Log/Normal plot, calculated the equation of the straight line, and reported directly the obtained inhibitions of plasma to the equation. The coefficient of correlation $\left(\mathrm{r}^{2}\right)$ of the Trolox linearized assay was $>0.996$. We have assayed 10 different plasma samples, collected on $\mathrm{K}_{3}$-EDTA, for their antioxidant activity, immediately after collection and after 1-4 freeze-thawing cycles. After one freeze/thawing cycle results were identical (see also Table 1). The same result was obtained from one to three freezing cycles, as shown in Figure 2A, for plasma volumes from 2 to $5 \mu \mathrm{l}$. In contrast, a complete annihilation of the plasma antioxidant capacity was observed after a fourth freezing cycle. The calculated $\mathrm{IC}_{50} \mathrm{~s}$, through sigmoidal fitting of the data presented in Figure 2A gave values of $3.36 \pm 0.44$, and $3.06 \pm 0.39 \mu \mathrm{l}$ of plasma, corresponding to $1.23 \pm 0.09 \mu \mathrm{g}$ of Trolox for 1 or two freezing cycles, not different from those reported in the original publication $(2.70 \pm 0.49 \pm 1$ of plasma, corresponding to 1.38 Trolox equivalents). In contrast, after three freezing cycles, $\mathrm{IC}_{50}$ was significantly reduced to $1.87 \pm 0.21 \mu \mathrm{l}$ of plasma, and annihilated after four freezing cycles. It was therefore concluded that plasma must be 


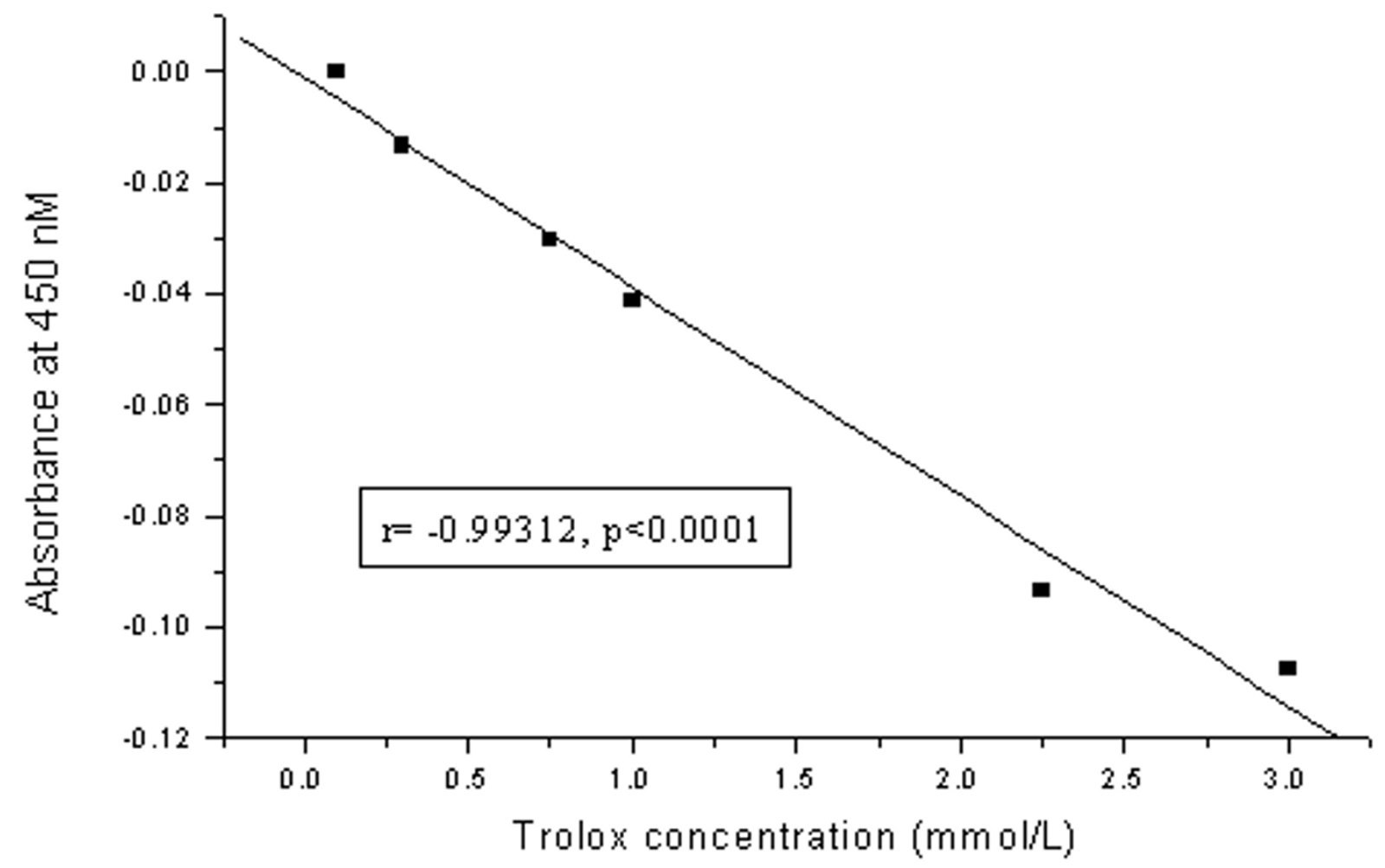

Figure 3

Linearity of the automated TAC assay A standard curve of $0-3 \mathrm{mmol} / \mathrm{L}$ of Trolox was assayed on an Olympus AU400 auto-analyzer. The results of the inhibition of crocin oxidation are presented as the absorbance at $450 \mathrm{~nm}$. A linear fit of the data is also presented.

used either immediately, or after a maximum of two freeze/thawing cycles.

Figure 2B presents the calculated TAC expressed as Trolox equivalent per $\mu$ l of plasma. As shown, minor changes in the calculated TAC/ $\mu$ l were found when 3.3-5 $\mu$ l of plasma were used in the assay and the number of freeze cycles was $<3$. In contrast, a linear decrease of the calculated TAC/ $\mu$ l was found when $2 \mu$ l of plasma were used. As expected from the data presented in Figure 2A, a dramatic decrease of the TAC was observed after four freezing cycles. The TAC per unit of volume calculated and presented in Figure $2 \mathrm{~B}(0.37 \pm 0.07 \mu \mathrm{g}$ of Trolox equivalent) is not significantly different from the one calculated from the $\mathrm{IC}_{50} \mathrm{~s}$ presented in Figure $2 \mathrm{~A}(0.38 \pm 0.04)$. In view of this result, we have therefore concluded that we could use a plasma volume between 3 and $5 \mu \mathrm{l}$, and calculate directly the TAC from the linearized Trolox curve. This method was further used in the following experiments.
Validation of automated TAC assay

Based on the above results, an automated assay has been developed, as described under Material and Methods. This assay was further validated in various experimental conditions:

TAC of human plasma

Linearity

As presented above, a major disadvantage of the manual method is non-linear Trolox standard curves. Therefore, a $\mathrm{Log} /$ Linear plot is needed, in order to calculate the results. It order to simplify the assay, and to make it suitable for an end-point determination on different auto-analyzers, we have modified the assay volumes and reagents, as described in the Material and Methods section. The obtained curve, assayed on an auto-analyzer was linear, over the range of 0-3 mmol/L (Figure 3), a concentration including the majority of the obtained values (see later results). 


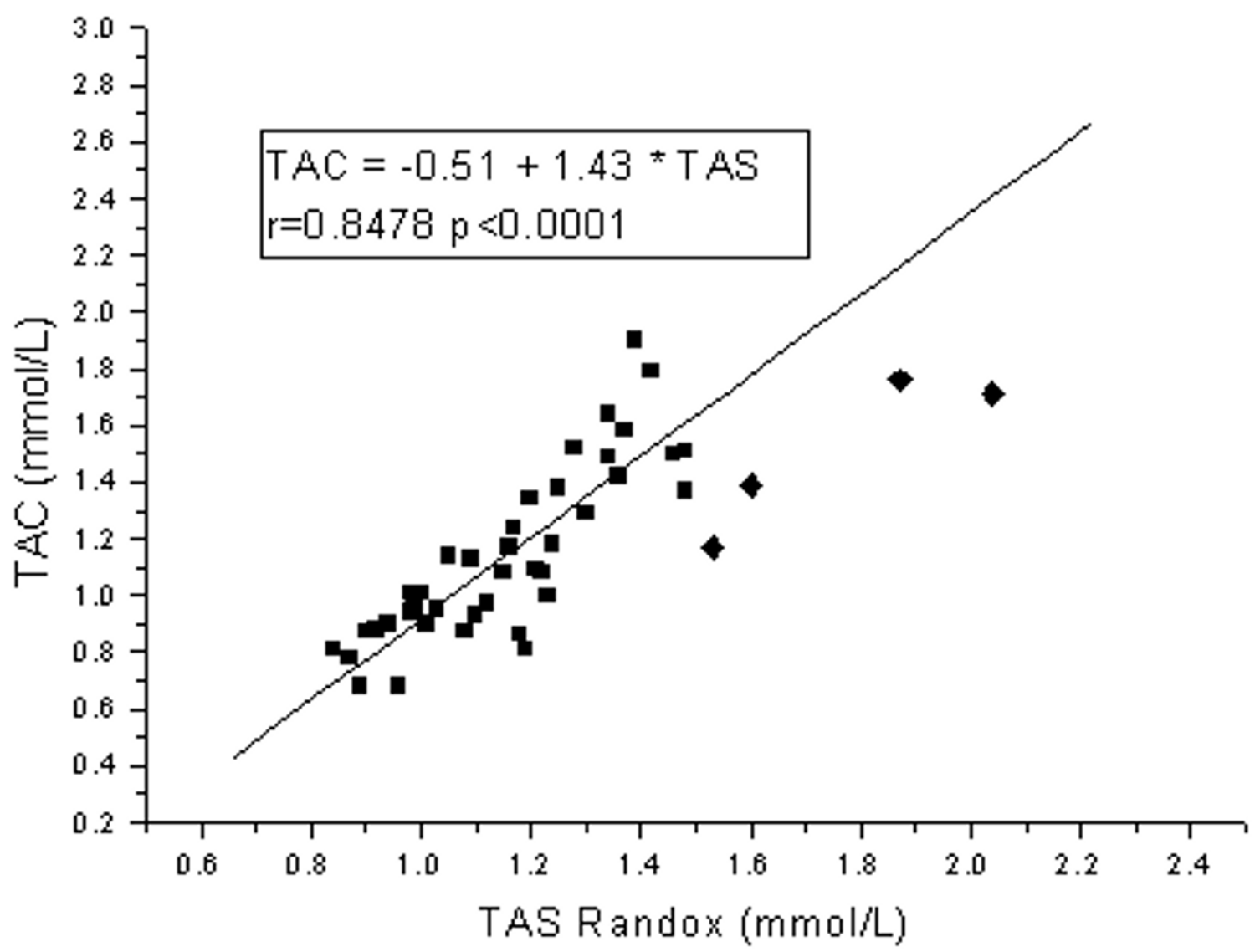

\section{Figure 4}

Correlation between TAC and TEAC Correlation of the TAC assay and the Randox Total Antioxidant Status assay (TAS), based on the TEAC method, initially described by Miller and Rice-Evans [2I-23]. Both assays were performed serially on the same autoanalyzer on 44 human plasma samples. Diamonds show four outliers.

\section{Correlation between TAC and TEAC}

The only fully automated method of plasma antioxidant activity in the market is the Total Antioxidant Status assay by Randox (Antrtim, UK), based on the TEAC method, initially described by Miller and Rice-Evans [21-23]. We have performed therefore both assays on a number of 44 human plasma samples. The results are presented in Figure 4. As shown, with the exception of four outliers (marked as diamonds) a very good linear correlation ( $\mathrm{r}=$ $0.8478, \mathrm{p}<0.0001$ ) was found between the two assays. Nevertheless, the intercept of the linear fit is $0.51 \mathrm{mmol} /$ $\mathrm{L}$, indicating that at low concentrations TAC results tend to be lower than the TAS assays, while the coefficient of the linear fit is 1.4, suggesting that these two assays based on the oxidation of different substances, might measure a slightly different number of circulating antioxidants.

\section{Reference values}

Based on a number of 44 human blood donors (freezed plasmas), the reference values of TAC were estimated to be $1.175 \pm 0.007 \mathrm{mmol} / \mathrm{L}$, similar to the RAS (Randox) assay of the total antioxidant status, which, estimated on the same samples was found to be $1.209 \pm 0.005 \mathrm{mmol} / \mathrm{L}$.

\section{Dilutions}

A concentration of $4.0 \mathrm{mmol} / \mathrm{L}$ of Trolox in normal saline was diluted serially, and assayed 10 times. In addition, the same dilution of Trolox was diluted in a plasma sample (target value $0.86 \mathrm{mmol} / \mathrm{L}) 1 / 1(\mathrm{v} / \mathrm{v})$, and assayed 10 times, performing serial dilutions in normal saline. The results, presented in Figure 5, show that the TAC assay show a linear relation of values in $\log / \log$ coordinates, indicating that dilution of plasmas do not introduce an interference in the TAC assay. In addition, the target value of 


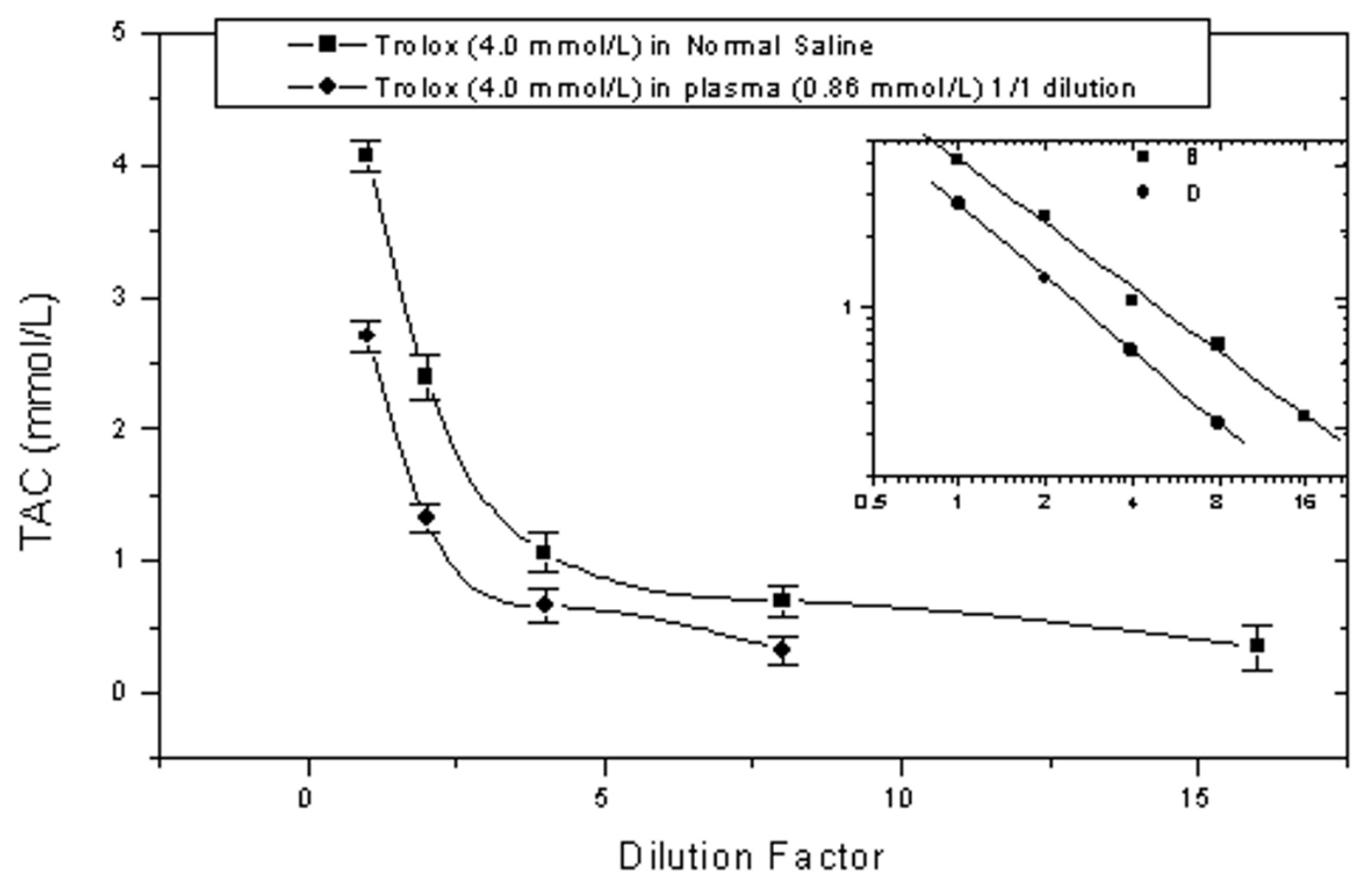

Figure 5

Effect of dilution on the TAC assay

plasma, in which a reference concentration of Trolox was introduced $(2.53 \mathrm{mmol} / \mathrm{L})$ was not significantly different from the one assayed by the TAC assay $2.705 \pm 0.170$ $\mathrm{mmol} / \mathrm{L})$.

\section{Effect of anticoagulants and storage}

A number of anticoagulants have been tested for blood collection, under different conditions. The obtained results are presented in Table 1 . As shown, heparin and $\mathrm{K}_{3^{-}}$ EDTA gave similar results, in all experimental conditions. In contrast, citrates decreased the TAC by about $20 \%$. Serum values, in the same samples, showed a $5 \%$ more elevated results.

\section{Effect of freezing}

A number of ten different plasma samples from normal individuals, collected on K-EDTA, were assayed after a number of 1-5 freeze/thawing cycles. As shown in Table 2 , one to three freezing cycles did not produce any difference in plasma TAC. In contrast, and inversely with the re- sults of the manual assay, a progressive increase of TAC values is found after 3 repeated freezing cycles. A possible explanation for the discrepancy of results between the manual and the automated method might be the fact that automated method, using smaller volumes of plasma, might be more sensitive to repeated freeze thawing, or alternatively, to plasma modifications produced by repeated freezing. Nevertheless, the fact that the automated method produces stable results during three freeze thawing cycles, makes it a robust technique for use in clinical practice.

Inter- and Intra-assay coefficient of variation

A number of ten different plasma samples, were assayed 10 times in the same run, after one freeze/thawing cycle, and in consecutive days, on a new aliquot, for the determination of intra- and inter-assay coefficient of variation. A $2.4 \%$ intra-assay CV and a $3.2 \%$ inter-assay CV were found. 
Table 2: Effect of repeated freezing cycles on TAC values

\begin{tabular}{lccccc}
\hline Anti-coagulant & \multicolumn{5}{c}{ Number of freeze/thawing cycles } \\
\cline { 2 - 6 } & $\mathbf{1}$ & $\mathbf{2}$ & $\mathbf{3}$ & $\mathbf{4}$ & $\mathbf{5}$ \\
& & & & & \\
\hline K-EDTA & & & & $1.13 \pm 0.03$ & $1.22 \pm 0.04$ \\
Heparin & $1.05 \pm 0.02$ & $1.00 \pm 0.02$ & $1.05 \pm 0.03$ & $1.24 \pm 0.04$ & $1.32 \pm 0.05$ \\
\hline
\end{tabular}

Ten different plasma samples from normal individuals, collected on $\mathrm{K}_{3}$-EDTA or heparin, were assayed after a number of $\mathrm{I}-5$ freeze/thawing cycles, by the automated TAC assay. Values are presented as the mean \pm SEM. The target value of non-freezed plasma, collected in a $K_{3}$-EDTA tube was given in Table I

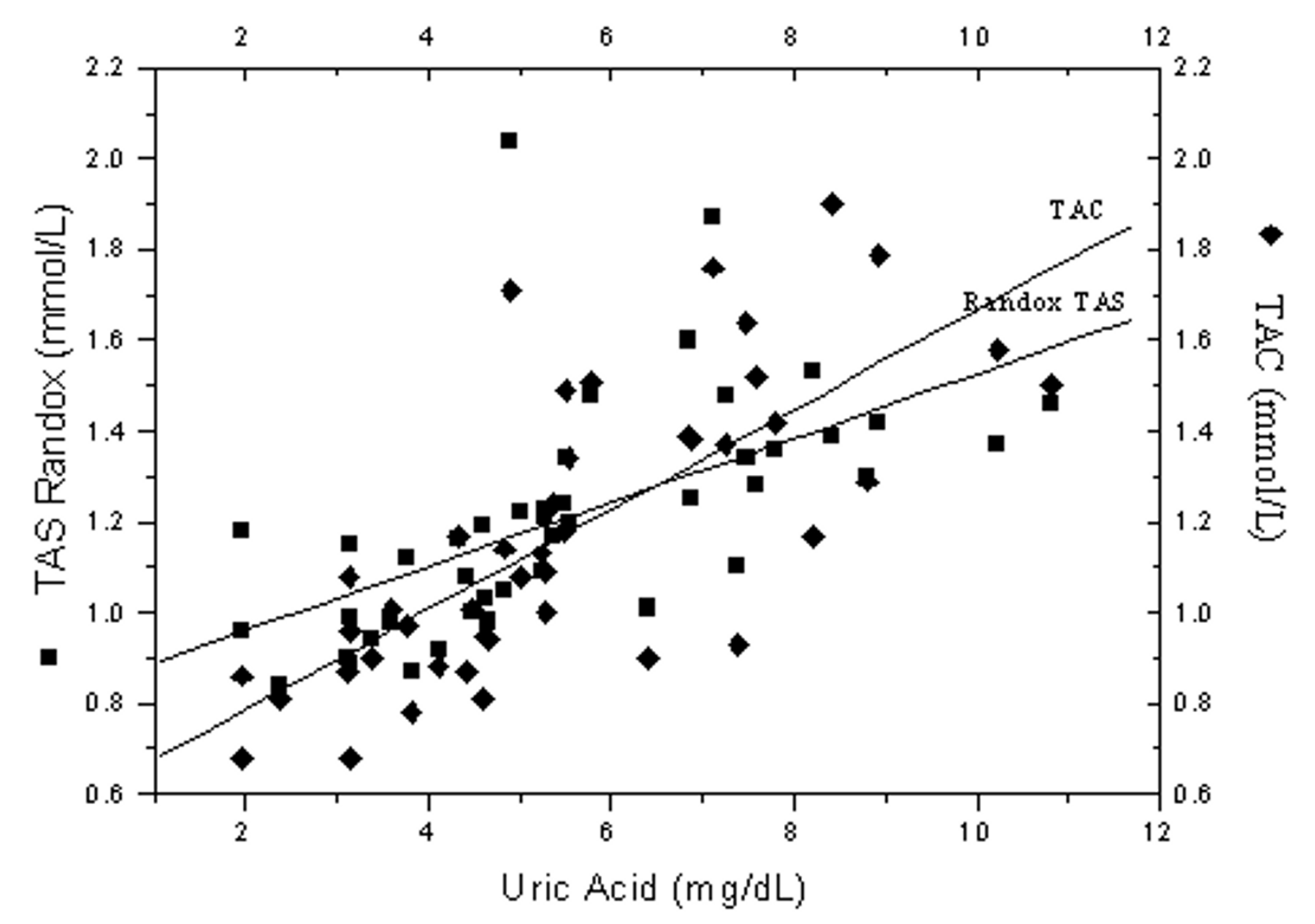

Figure 6

Correlation of TAC and Randox TAS assays with uric acid concentration of human plasmas. The assay was performed on 44 human plasma samples, serially using the two assays, on the same autoanalyzer (Olympus AU400). Squares represent TAS results, while diamonds represent TAC results. The straight lines and the correlation equations are also shown. 


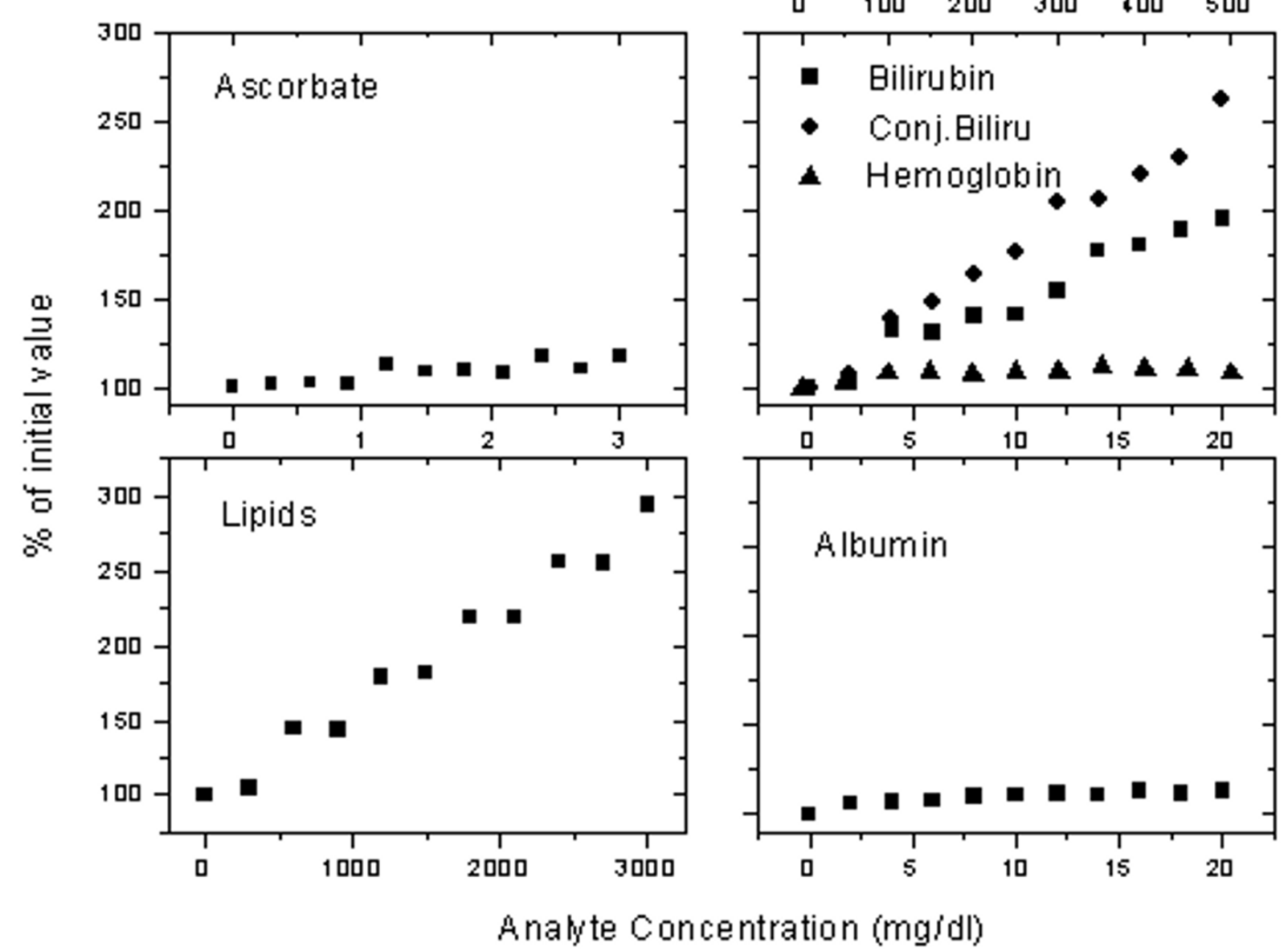

Figure 7

Effect of different analytes on the TAC assay

Effect of endogenous substances

As indicated in the Introduction, a number of investigators have proposed that uric acid, ascorbate or plasma proteins could interfere with the measurement of TAC, or they may represent the major component of TAC [2-5]. In addition, as the measurement of absorbance of crocin bleaching is performed at $450 \mathrm{~nm}$, bilirubin could interfere with the assay [18]. We have therefore tested these contributions in the automated TAC assay.

\section{Uric Acid}

Figure 6 shows the correlation of TAC and TAS assays on uric acid concentration of human plasmas. As shown, straight lines crossed the ordinate axes at 0.57 and 0.82 $\mathrm{mmol} / \mathrm{L}$ of TAC and TAS respectively. This result indicates that about $49 \%$ of the measured TAC activity is due to uric acid, significantly lower than the contribution of TAS on uric acid, calculated to $68 \%$. The slope of the straight line obtained between TAC and uric acid indicates that 0.11 $\mathrm{mmol} / \mathrm{L}$ of TAC correspond to $1 \mathrm{mg} / \mathrm{dl}$ of uric acid.

\section{Other endogenous substances}

In order to evaluate the interference of a number of other endogenous substances, we have performed the introduction in given samples of varying concentrations of ascorbate, lipids, bilirubin (total and conjugated) and hemoglobin. Our results (Figure 7), presented as an increased TAC over the sample concentration, show that ascorbate shows a statistically significant relationship of TAC values $(\mathrm{r}=0.86, \mathrm{p}<0.0001)$. Analysis of the results indicates that there is a slope of $0.07 \mathrm{mmol} / \mathrm{L}$ of TAC per $\mathrm{mg} / \mathrm{dl}$ of ascorbate. Bilirubin represents a possible interference to the TAC assay [18], due to its antioxidant capacity and to the fact that it presents an absorption maximum 


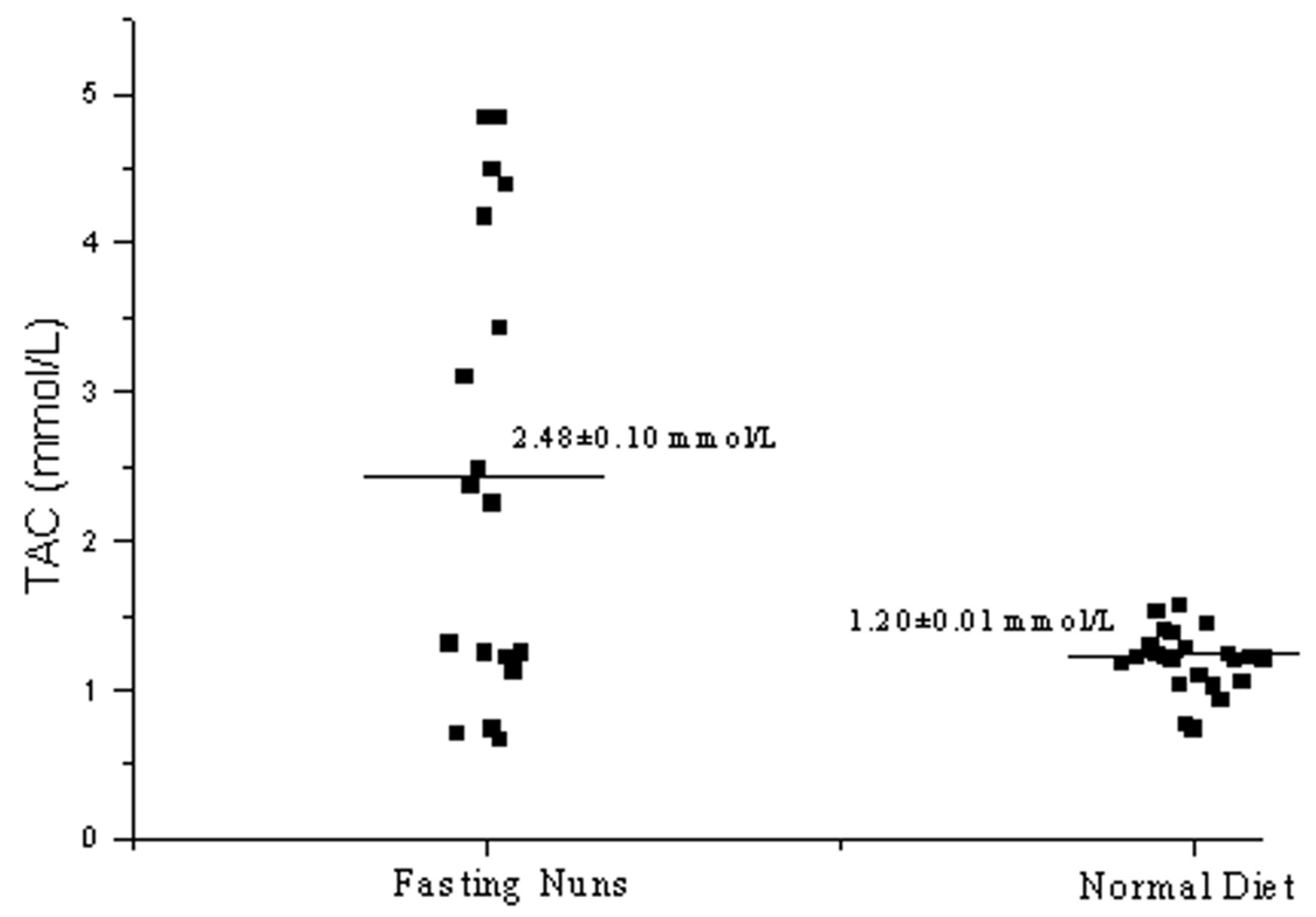

\section{Figure 8}

Effect of diet on the TAC values in human plasma. TAC assay of 17 samples taken from nuns, from a local monastery, after 40 days of ritual fasting. Their diet, during this period, was exempted of any animal food, and rich in fruits, vegetables, and extra-virgin olive oil, and compared the obtained results with 12 normal blood donors. Each dot presents an individual. Mean values \pm SEM are also shown

at $450 \mathrm{~nm}$, a wavelength used in the TAC assay. Indeed, as shown in Figure 7, a significant correlation could be observed with increasing bilirubin concentrations varying from $0-20 \mathrm{mg} / \mathrm{dl}(\mathrm{r}=0.98, \mathrm{p}<0.0001)$. Analysis of the linear fit indicated an increase of $0.14 \mathrm{mmol} / \mathrm{L}$ of TAC per $\mathrm{mg} / \mathrm{dl}$ of bilirubin. Taking into account that normal bilirubin values are lower than $1 \mathrm{mg} / \mathrm{dl}$, it was concluded that about $12 \%$ of TAC might be attributed to this analyte. Nevertheless, a higher interference might be expected in icteric patients. The same linear correlation is also found with the water-soluble conjugated bilirubin concentration. In this case, the interference was $0.11 \mathrm{mmol} / \mathrm{L}$ of TAC per mg/dl of conjugated bilirubin. In contrast, hemo- globin did not show any significant relationship in the TAC assay. Albumin is one of the oxidant scavenger systems in plasma. Nevertheless, as shown in Figure 7, a minor interference of albumin (ranging from 0 to $20 \mathrm{mg} / \mathrm{dl}$ ) was found on the TAC assay. A significant correlation ( $\mathrm{r}=$ $0.8992, \mathrm{p}<0.0004$ ) was observed, while an interference of $0.01 \mathrm{mmol} / \mathrm{L}$ of TAC was observed per $\mathrm{mg}$ albumin/dl. Finally, total lipids show a strong correlation with TAC $(r=$ $0.99, \mathrm{p}<0.0001$ ) with an increase in TAC of 0.18 per 100 $\mathrm{mg} / \mathrm{dl}$ of lipids, indicating a participation of $30 \%$ in the TAC assay. 
Summarizing therefore the different contributions found, we have concluded that about $85 \%$ of TAC, in normal subjects, is due to endogenous antioxidants, and only about $15 \%$, under normal circumstances is due to exogenously (dietary provided) antioxidant substances.

\section{Effect of diet}

The above conclusion indicates that exogenously provided antioxidants might modify the TAC of human plasma. In order to investigate this possibility, we have measured the TAC of 17 samples taken from nuns, from a local monastery, after 40 days of ritual fasting. Their diet, during this period, was exempted of any animal food, and was rich in fruits, vegetables, and extra-virgin olive oil. The results of TAC assay are presented in Figure 8. As shown, the distribution of TAC in the nuns' group is broader, and the mean value higher than in samples from normal individuals (mean values \pm SEM $2.48 \pm 0.10$ as compared to $1.20 \pm 0.01 \mathrm{mmol} / \mathrm{L}, \mathrm{t}$-value $12.8, \mathrm{p}<0.0001$ ). This high increase of TAC was attributed to the fasting diet followed by this group, as all other analyte measurements were comparable between the two groups.

\section{Discussion}

Reactive oxygen species (ROS) as well as reactive nitrogen species (RNS) are produced as a consequence of normal aerobic metabolism in animal species [24-26]. These "free radicals" are removed and/or inactivated in vivo by a battery of antioxidants [4,24-27]. A biological antioxidant is defined as a substance, which, at low concentrations compared to that of the oxidisable substrate, significantly delays or prevents this oxidation $[6,27,28]$. Individual members of the antioxidant defense team are employed to prevent the generation of free ROS and RNS, to destroy potential antioxidants and to scavenge ROS and RNS. However, the relative sufficiency of the organism antioxidant defenses is critical in the development of oxidative stress in patients affected by a number of diseases, including HIV infections $[29,30]$, neurodegeneration [31], diabetes [3,32-34], angina [35-38], certain forms of cancer [39-47], and probably ageing [48-50]. These diseases are characterized by an overproduction of free radicals, i.e. when the antioxidant defense of an organism is overwhelmed or are established when a deficit of defenses of the organism against oxidation occurs.

The primary defense against oxidative stress in extracellular fluids results from a number of low molecular weight antioxidant molecules either water - (ex. ascorbic acid) or lipid-soluble (ex. Vitamin E). These antioxidants can also be generated during normal metabolism (ex. uric acid, bilirubin, albumin, thiols) or introduced in the body by the consumption of dietary products rich in antioxidants (olive oil, fruits and vegetables, tea, wine, etc) [6]. The sum of endogenous and food-derived antioxidants represents the total antioxidant activity of the extracellular fluid. In addition, the levels of these antioxidants are suitable not only as a protection against oxidation, but could also reflect their consumption during acute oxidative stress states. The cooperation among different antioxidants provides a greater protection against attack by reactive oxygen or nitrogen radicals, than any single compound alone. Thus, the overall antioxidant capacity may give more relevant biological information compared to that obtained by the measurement of individual parameters, as it considers the cumulative effect of all antioxidants present in plasma and body fluids [51]. A theory has recently be proposed, taking into account the redox potentials of exogenous and endogenous antioxidants, and the construction of a chained reaction, in which a given antioxidant, after oxidation is regenerated through a number of reactions involving a number of other, more potent antioxidants. Through this cascade, interactions among the lipid and the aqueous phases could be established [52].

A great variety of methods have been proposed for the assay of total antioxidant activity or capacity of serum or plasma [reviewed extensively and critically in $[6,51]]$. In these reviews a clear distinction among antioxidant activity and capacity is made: Antioxidant activity corresponds to the rate constant of a single antioxidant against a given free radical. Antioxidant capacity, on the other hand, is the measure of moles of a given free radical scavenged by a test solution, independently of the capacity of any one antioxidant present in the mixture [51]. Therefore, for plasma, being a heterogeneous solution of diverse antioxidants, the antioxidant status is better reflected by antioxidant capacity rather than activity. This capacity is a combination of all the redox chain antioxidants, including different analytes such as thiol bearing proteins, and uric acid. Therefore, the plasma antioxidant capacity is rather a concept than a simple analytical determination. Indeed, an increase of the antioxidant capacity of plasma indicates absorption of antioxidants and an improved in vivo antioxidant status [53], or an adaptation mechanism to an increased oxidative stress. Nevertheless, due to the participation of diverse metabolites (see Figures 6 and 7) to the antioxidant capacity of human plasma, its increase may not be necessarily a desirable condition. Indeed, in some cases, such as renal failure (uric acid), icteric status (bilirubin), hepatic damage (hypoalbuminemia) the variation of several metabolites falsely modifies the plasma antioxidant capacity, a situation returning to normal values after correction of the underlying disease [54].

As derived from the definition of antioxidant capacity, and the heterogeneity of antioxidant substances in human plasma, all methods used for its determination are by definition indirect [6]. The crocin bleaching method, used in the present paper, initially described by Tubaro et al [17], 
and Lusignoli et al [18] uses crocin oxidation by peroxyl radicals produced by ABAP. By comparing the inhibition of bleaching (oxidation) of crocin by plasma, to an artificial antioxidant (Trolox C), either kinetically [17], or at end point [18], a standard antioxidant capacity of plasma can be derived, expressed as Trolox equivalent. As discussed by Prior and Cao [6], a serious problem of the crocin method is the lag time phase, when lipids and proteins act as antioxidants, a result not encountered in the modification proposed here (Figure 7), at analyte concentrations exceeding by far the reference values in human plasma. In addition, concerning ascorbic acid (that the previous kinetic method provides values exceeding all other reported, 7.7 Trolox equivalents) was not a problem in the current assay. Indeed, ascorbic acid accounted (on a molar basis) only for 1.22 Trolox equivalents. Compared to another commercialized antioxidant capacity determination (Total Antioxidant Status by Randox) (see Figure 4), a significant linear correlation was observed, while TAC assay tends to assay lower AC by $0.5 \mathrm{mmol} / \mathrm{L}$, expressed as Trolox equivalents. The TAS assay is based on the TEAC (Trolox Equivalent Antioxidant Capacity) method, reported by Miller and Rice-Evans [21-23]. It is based on the inhibition by antioxidants of the absorbance of the radical cation of 2,2'-azinobis-(3-ethylbenzothiazoline-6sulfonate) (ABTS) formed by the interaction of ABTS with ferrylmyoglobin radical species. This, also indirect, method gave similar reference values as the TAC assay, on 44 healthy blood donors (TAS: $1.209 \pm 0.005 \mathrm{mmol} / \mathrm{L}$; TAC: $1.175 \pm 0.007 \mathrm{mmol} / \mathrm{L}$ of Trolox equivalents), measured serially on the same autoanalyzer.

As discussed elegantly by Prior et al [6], different metabolites interfere with all indirect antioxidant capacity methods. These endogenous analytes include uric acid, ascorbate, albumin, bilirubin and lipoproteins. During the validation of the TAC assay we performed analysis of the above metabolites on the antioxidant capacity. We have found that uric acid, bilirubin, ascorbate and lipoproteins accounted for $0.11 \mathrm{mmol} / \mathrm{mg}$, $0.14 \mathrm{mmol} / \mathrm{mg}$, $0.07 \mathrm{mmol} / \mathrm{mg}$, and $0.18 \mathrm{mmol} / 100 \mathrm{mg}$ respectively. Taking into account the normal concentrations of these analytes, it was concluded that about $1 \mathrm{mmol} / \mathrm{L}$ (i.e. about $85 \%$ of the TAC) is due to endogenous analytes, and only $15 \%$ of the observed TAC might be due to exogenously provided antioxidants. Of course, as our reference subjects were blood donors, we could not have precise evaluation of their dietary and smoking habits. Indeed, it is well established that smoking habits reduce the TAC of human plasma, a reduction which is reversed after stopping smoking [51]. Non-smoking nuns, following a diet rich in antioxidant substances, increase dramatically their TAC of plasma, demonstrating the importance of dietary antioxidants (Figure 8).

\section{Conclusions}

As discussed above, the AC of plasma might be considered as a concept rather than a pure analytical determination. Taking into consideration the participation of major analytes in the bleaching of crocin, we propose the measurement of TAC in relation to these metabolites, in order to estimate the contribution of exogenous substances to the total antioxidant capacity. In this way, the possible interference of endogenous and exogenous antioxidants can be evaluated and tested in diverse physiological and pathological situations. The TAC assay, fully automated, stable and reliable could, in such a way be of value in the estimation of the AC of plasma, and the role of different kind of foods and beverages, with presumed or definite role in human health, could be evaluated.

\section{Authors' contributions}

MK carried out the whole development of the method, AN contributed at the initial development of TAC assay, VT developped the automated technique and the initial interference studies, NM performed the assays and validation of the automated assay, GN participated at the development of the automation on the Triturus plate automate, and EC conceived, designed and supervised the whole study.

All authors read and approved the final manuscript.

\section{Abbreviations used}

ABAP: 2,2'-Azobis-(2-amidinopropane) dihydrochloride; TAC: Total Antioxidant Capacity; TAS: Total Antioxidant Status; Trolox: 6-hydroxy-2,5,7,8-tetramethylchroman-2carboxylic acid

\section{Acknowledgements}

Work partially supported by the University of Crete, Research Committee. Professor A. Margioris is deeply acknowledged for the stimulating discussions and for reviewing a version of the present work.

\section{References}

I. Duthie GG: Determination of activity of antioxidants in human subjects. Proc Nutr Soc 1999, 58:1015-24

2. Wayner DD, Burton GW, Ingold KU, Barclay LR, Locke SJ: The relative contributions of vitamin $E$, urate, ascorbate and proteins to the total peroxyl radical-trapping antioxidant activity of human blood plasma. Biochim Biophys Acta 1987, 924:408-19

3. Ceriello A, Bortolotti N, Crescentini A, Motz E, Lizzio S, Russo A, Ezsol Z, Tonutti L, Taboga C: Antioxidant defenses are reduced during the oral glucose tolerance test in normal and non-insulin-dependent diabetic subjects. Eur J Clin Invest 1998, 28:32933

4. Frei B, Stocker R, Ames BN: Antioxidant defenses and lipid peroxidation in human blood plasma. Proc Natl Acad Sci U S A 1988, 85:9748-52

5. Ryan M, Grayson L, Clarke DJ: The total antioxidant capacity of human serum measured using enhanced chemiluminescence is almost completely accounted for by urate. Ann Clin Biochem 1997, 34:688-9

6. Prior RL, Cao G: In vivo total antioxidant capacity: comparison of different analytical methods. Free Radic Biol Med 1999, 27: || $73-8 \mid$ 
7. Rice-Evans C, Miller N: Measurement of the antioxidant status of dietary constituents, low density lipoproteins and plasma. Prostaglandins Leukot Essent Fatty Acids 1997, 57:499-505

8. Wayner DD, Burton GW, Ingold KU, Locke S: Quantitative measurement of the total, peroxyl radical-trapping antioxidant capability of human blood plasma by controlled peroxidation. The important contribution made by plasma proteins. FEBS Lett 1985, 187:33-7

9. Aejmelaeus R, Ketela TM, Pirttila T, Hervonen A, Alho H: Unidentified antioxidant defenses of human plasma in immobilized patients: a possible relation to basic metabolic rate. Free Radic Res 1997, 26:335-41

10. Ghiselli A, Serafini M, Maiani G, Azzini E, Ferro-Luzzi A: A fluorescence-based method for measuring total plasma antioxidant capability. Free Radic Biol Med 1995, I 8:29-36

II. DeLange RJ, Glazer AN: Phycoerythrin fluorescence-based assay for peroxy radicals: a screen for biologically relevant protective agents. Anal Biochem 1989, I77:300-6

12. Glazer AN: Phycoerythrin fluorescence-based assay for reactice oxygen species. Meth Enzymol 1990, I 86:161-168

13. Abella A, Messaoudi C, Laurent D, Marot D, Chalas J, Breux J, Claise C, Lindenbaum A: A method for simultaneous determination of plasma and erythrocyte antioxidant status. Evaluation of the antioxidant activity of vitamin $E$ in healthy volunteers. $B$ J Clin Pharmacol 1996, 42:737-4I

14. Benzie IFF, Strain Jl: The ferric reducing ability of plasma (FRAP) as a measure of "antioxidant power": the FRAP assay. Anal Biochem 1996, 239:70-6

15. Dasgupta A, Malhotra D, Levy H, Marcadis D, Blackwell W, Johnston D: Decreased total antioxidant capacity but normal lipid hydroperoxide concentrations in sera of critically ill patients. Life Sci 1997, 60:335-40

16. Dasgupta A, Zdunek T: In vitro lipid peroxidation of human serum catalyzed by cupric ion: antioxidant rather than prooxidant role of ascorbate. Life Sci 1992, 50:875-82

17. Tubaro F, Ghiselli A, Rapuzzi P, Maiorino M, Ursini F: Analysis of plasma antioxidant capacity by competition kinetics. Free Radic Biol Med 1998, 24: 1228-34

18. Lussignoli S, Fraccaroli M, Andrioli G, Brocco G, Bellavite P: A microplate-based colorimetric assay of the total peroxyl radical trapping capability of human plasma. Anal Biochem 1999 269:38-44

19. Jorgensen LV, Andersen HJ, Skibsted LH: Kinetics of reduction of hypervalent iron in myoglobin by crocin in aqueous solution. Free Radic Res 1997, 27:73-87

20. Papadopoulos G, Boskou D: Antioxidant effect of natural phenols on olive oil. J. Am. Oil Chem. Soc. 1991, 68:669-67|

21. Miller NJ, Rice-Evans C, Davies MJ, Gopinathan V, Milner AA: A novel method for measuring antioxidant capacity and its application to monitoring the antioxidant status in neonates. Clin Sci 1993, 84:407-4I2

22. Rice-Evans $\mathrm{C}$, Miller NJ: Total antioxidant status in plasma and body fluids. Meth Enzymol 1994, 234:279-293

23. Re R, Pellegrini N, Proteggente A, Pannala A, Yang M, Rice-Evans C: Antioxidant activity applying an improved ABTS radical cation decolorization assay. Free Radic Biol Med I999, 26: I23 I-I237

24. Gutteridge JM: Biological origin of free radicals, and mechanisms of antioxidant protection. Chem Biol Interact 1994, 9 I: I3340

25. Halliwell B: Antioxidants and human disease: a general introduction. Nutr Rev 1997, 55:S44-9

26. Halliwell B: Free radicals and antioxidants: a personal view. Nutr Rev 1994, 52:253-65

27. Halliwell B, Gutteridge JM: The antioxidants of human extracellular fluids. Arch Biochem Biophys 1990, 280: I-8

28. Halliwell B, Gutteridge JM: The definition and measurement of antioxidants in biological systems. Free Radic Biol Med 1995 , I8: $125-6$

29. McLemore JL, Beeley P, Thorton K, Morrisroe K, Blackwell W, Dasgupta A: Rapid automated determination of lipid hydroperoxide concentrations and total antioxidant status of serum samples from patients infected with HIV: elevated lipid hydroperoxide concentrations and depleted total antioxidant capacity of serum samples. Am J Clin Pathol 1998, 109:268-73
30. Greenspan HC, Aruoma Ol: Oxidative stress and apoptosis in HIV infection: a role for plant-derived metabolites with synergistic antioxidant activity. Immunol Today 1994, 1 5:209-13

31. Kok AB: Ascorbate availability and neurodegeneration in amyotrophic lateral sclerosis. Med Hypotheses 1997, 48:28I-96

32. Baynes JW, Thorpe SR: Role of oxidative stress in diabetic complications: a new perspective on an old paradigm. Diabetes 1999, 48:1-9

33. Baynes JW: Role of oxidative stress in development of complications in diabetes. Diabetes 1991, 40:405-12

34. Tsai EC, Hirsch IB, Brunzell JD, Chait A: Reduced plasma peroxyl radical trapping capacity and increased susceptibility of LDL to oxidation in poorly controlled IDDM. Diabetes 1994, 43: $1010-4$

35. Riemersma RA, Carruthers KF, Elton RA, Fox KA: Plasma ascorbic acid and risk of heart disease and cancer. Lancet 200I, 357:2136-7

36. Riemersma RA, Wood DA, Macintyre CC, Elton RA, Gey KF, Oliver MF: Anti-oxidants and pro-oxidants in coronary heart disease. Lancet 1991, 337:677

37. Riemersma RA, Wood DA, Macintyre CC, Elton RA, Gey KF, Oliver MF: Risk of angina pectoris and plasma concentrations of vitamins A, C, and $\mathbf{E}$ and carotene. Lancet |99|, 337:|-5

38. Riemersma RA: Coronary heart disease and vitamin E. Lancet 1996, 347:776-7

39. Emerit I: Reactive oxygen species, chromosome mutation, and cancer: possible role of clastogenic factors in carcinogenesis. Free Radic Biol Med 1994, 16:99-109

40. Mantovani G, Maccio A, Madeddu C, Mura L, Gramignano G, Lusso MR, Mulas C, Mudu MC, Murgia V, Camboni P, et al: Quantitative evaluation of oxidative stress, chronic inflammatory indices and leptin in cancer patients: correlation with stage and performance status. Int J Cancer 2002, 98:84-91

4I. Farhadi A, Fields J, Banan A, Keshavarzian A: Reactive oxygen species: are they involved in the pathogenesis of GERD, Barrett's esophagus, and the latter's progression toward esophageal cancer? Am / Gastroenterol 2002, 97:22-6

42. Ross JS, Stagliano NE, Donovan MJ, Breitbart RE, Ginsburg GS: Atherosclerosis and cancer: common molecular pathways of disease development and progression. Ann N Y Acad Sci 200I, 947:27|-92

43. Abiaka C, Al-Awadi F, Al-Sayer H, Gulshan S, Behbehani A, Farghally $M$, Simbeye A: Serum antioxidant and cholesterol levels in patients with different types of cancer. J Clin Lab Anal 200 I, I 5:324-

44. Wenger FA, Kilian M, Ridders J, Stahlknecht P, Schimke I, Guski H, Jacobi CA, Muller JM: Influence of antioxidative vitamins A, C and $E$ on lipid peroxidation in BOP-induced pancreatic cancer in Syrian hamsters. Prostaglandins Leukot Essent Fatty Acids 2001, 65: 165-7|

45. Raung SL, Kuo MD, Wang YM, Chen C]: Role of reactive oxygen intermediates in Japanese encephalitis virus infection in murine neuroblastoma cells. Neurosci Lett 200I, 315:9-12

46. Williams KJ, Cowen RL, Stratford IJ: Hypoxia and oxidative stress. Tumour hypoxia-therapeutic considerations. Breast Cancer Res 200I, 3:328-31

47. Brown NS, Bicknell R: Hypoxia and oxidative stress in breast cancer. Oxidative stress: its effects on the growth, metastatic potential and response to therapy of breast cancer. Breast Cancer Res 200I, 3:323-7

48. Vanderjagt DJ, Garry PJ, Bhagavan HN: Ascorbic acid intake and plasma levels in healthy elderly people. Am J Clin Nutr I987, 46:290-4

49. Vanderjagt DJ, Garry PJ, Bhagavan HN: Ascorbate and dehydroascorbate: distribution in mononuclear cells of healthy elderly people. Am J Clin Nutr 1989, 49:5 I I-6

50. Stauber PM, Sherry B, Vanderlagt DJ, Bhagavan HN, Garry PJ: A longitudinal study of the relationship between vitamin $A$ supplementation and plasma retinol, retinyl esters, and liver enzyme activities in a healthy elderly population. Am J Clin Nutr |991, 54:878-83

51. Ghiselli A, Serafini M, Natella F, Scaccini C: Total antioxidant capacity as a tool to assess redox status: critical view and experimental data. Free Radic Biol Med 2000, 29: I I06-I4

52. Barbaste M, Verge S, Dumas M, Soulet S, Nay B, Arnaudinaud V, Delaunay J-C, Castagnino C, Cheze C, Vercauteren J: Dietary antioxi- 
dants, peroxidation and cardiovascular risks. J Nutr Health Aging 2002, 6:138-152

53. Cao G, Booth SL, Sadowski JA, Prior RL: Increases in human plasma antioxidant capacity following consumption of controlled diets high in fruits and vegetables. Am J Clin Nutr 1998, 68: I08I1087

54. Jackson P, Loughrey CM, Lightbody JH, McNamee PT, Young IS: Effect of hemodialysis on total antioxidant capacity and serum antioxidants in patients with chronic renal failure. Clin Chem 1995, 4I: II35-II38

\section{Pre-publication history}

The pre-publication history for this paper can be accessed here:

http://www.biomedcentral.com/1472-6890/2/3/prepub

Publish with BioMed Central and every scientist can read your work free of charge

"BioMedcentral will be the most significant development for disseminating the results of biomedical research in our lifetime." Paul Nurse, Director-General, Imperial Cancer Research Fund

Publish with BMC and your research papers will be:

- available free of charge to the entire biomedical community

- peer reviewed and published immediately upon acceptance

- cited in PubMed and archived on PubMed Central

- yours - you keep the copyright

Submit your manuscript here:

BioMedcentral.com editorial@biomedcentral.com 